\title{
ERJ
}

Engineering Research Journal

Faculty of Engineering

Menoufia University

\section{Practical Study of Sustainable Green Building Materials: Faculty of Engineering Building, Menoufia University}

\author{
Salwa Mostafa Shehata \\ Department of Architectural Engineering, University of Menoufia, Egypt. \\ salwashehataeg@yahoo.com
}

\begin{abstract}
:
Indoor spaces represent the most important places in people's life where they live, learn, work and they spend more of their time indoors. Thus, improving the indoor environmental quality is considered as an important step for the human health and well-being. The research discusses the main categories of indoor environmental quality (IEQ): indoor air quality, Daylight and visual comfort, and thermal comfort, where these categories are affected by traditional building materials that directly influence negatively on building's occupants. Furthermore, building materials must not only do less harm but go further and regenerate the natural and social environments. The research aimed to find out some Nano-materials that can improve the indoor environment quality and overcoming the problems related to the environmental aspects in the educational buildings.

The building of Architecture and civil in the faculty of engineering of Menoufia University is presented as a case study, as it underwent problems and deficiencies related to environmental aspects. Post Occupancy Evaluation will evaluate IEQ indicators based on the occupant's opinions. The results of the research will interpret the emphasis of applying the Nano photo-catalyst materials that may positively affect indoor environmental quality and promote occupants' comfort, well-being and productivity.
\end{abstract}

Index Terms: Indoor environmental quality, Nano-materials, Green millennium photo-catalyst, Post Occupancy Evaluation.

\section{INTRODUCTION}

Green building with High indoor environmental quality protects the health and comfort of building occupants, enhance productivity, decrease absenteeism, improve a building's value and reduce liability for building designers and owners [1]. Materials performance is one of the main factors for a green building to improve indoor quality and overcoming the air pollution. To understand the relationship between materials and resources and indoor environmental quality, rating systems such as LEED and GPRS standard must be checked.

LEED (Building Design and Construction): The most widely used rating system globally.

Green Pyramid Rating System (GPRS) Public Review: This is national green building rating system in Egypt; developed by the Housing and Building National Research Center.

The Indoor Environmental Quality (EQ) category in LEED rewards decisions made by project teams about indoor air quality and thermal, visual, and acoustic comfort [2]. In GPRS this category supports the wellbeing and comfort of occupants by providing sufficient outside air ventilation and indoor air quality. It is also encouraging use of low-emission adhesives, sealants, paints, coatings, flooring and ceiling systems [3].

The Research Problem
Traditional building materials can't improve indoor environmental quality, it even causes environmental and health problems because it contains formaldehyde, which used widely by industry to manufacture building materials and numerous household products. Therefore, using environmentally preferable materials becomes a necessity. Nanotechnology is one of the modern trends in building materials which have the properties that improve air quality, light and thermal comfort.

\section{The Research Aim}

The general aim of this research is to develop a framework combines all factors which affect the indoor environment, and to find out the suitable environmentally preferable materials that improve all these factors. The building of Architecture and civil in the faculty of engineering of Menoufia University selected as a case study was chosen for some renovations to reach the research objective which is to overcome the indoor air quality problems and enable students and staff to perform their work effectively during the different educational activities.

\section{The Research Methodology}

The methodology adopted in the research is qualitative. The research methodology is shown in fig.1. The literature review is presented followed by the Post Occupancy Evaluation which is the process of obtaining feedback on a 
building's performance in use and valuable in all construction sectors, especially education where poor building performance will impact the occupant's well-being and business efficiency. The tools used for the case study building evaluation are the questionnaire survey and supplemented by a walk-through observation.

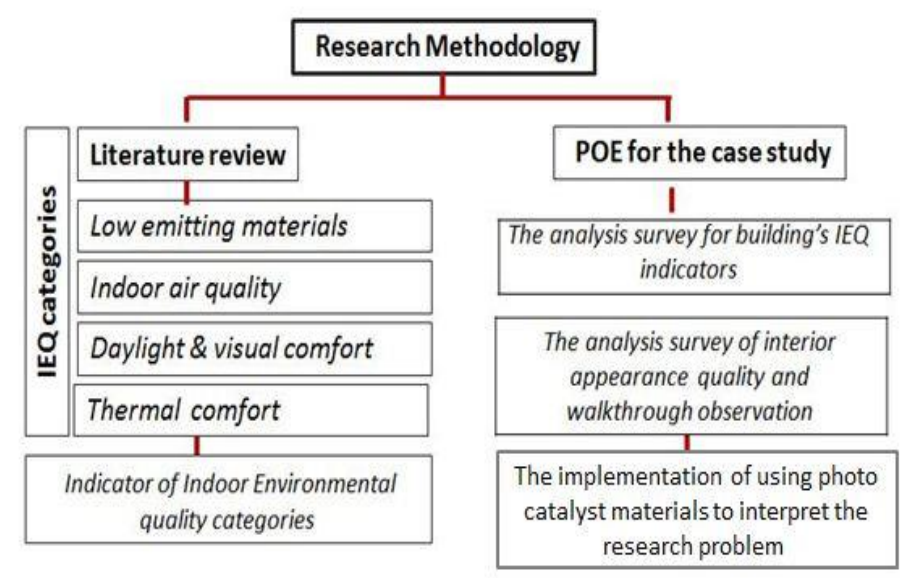

Fig. 1 Research Methodology (Researcher)

Indoor environmental quality addresses the myriad design strategies and environmental factors air quality, lighting quality, acoustic design, and control over one's surroundings [2]. The following aspects are addressed in the literature review:

1- Low emitting materials

2- Indoor air quality

3- Daylight and visual comfort

4- Thermal comfort

\section{LITERATURE REVIEW}

The literature review illustrates the IEQ categories and the influence of using Nano photo catalyst - Green Millenniur materials as follow:

\section{A. Low emitting materials}

Low emitting materials aim to reduce concentrations of chemical contaminants that can damage air quality, human health, productivity, and the environment [2]. Volatile organic compounds (VOCs) are chemicals that are released into the air from numerous materials; those organic compounds may cause a wide range of chronic health problems. The Nano photc catalyst materials such as green millennium photo catalys 1 doesn't emit any organic compounds, it is also having a deodorizing effect which prevents smoke, bacteria, virus and harmful gas with the help of the highly oxidizing effect of photo-catalyst (Ti02).

Green millennium Photo-catalyst Products comply all the Photo-catalysis Industry Association of Japan (PIAJ) testing methods and standards. Among product certification, the
Photo-catalysis PIAJ has set the industrial standards guidance which requires the photo-catalyst product to pass certain performance guideline [4]. Green millennium can be adopted to promote LEED certification. LEED points are awarded for use photo-catalytic will obtain a variety of credit points in the "New Construction and Major Renovation" Categories LEED rating system [5]. Green millennium deodorizing effect accelerates the breakdown of VOCs by destroying the molecular bonds in addition to a various environmental property which affect the indoor environment as shown in fig.2.

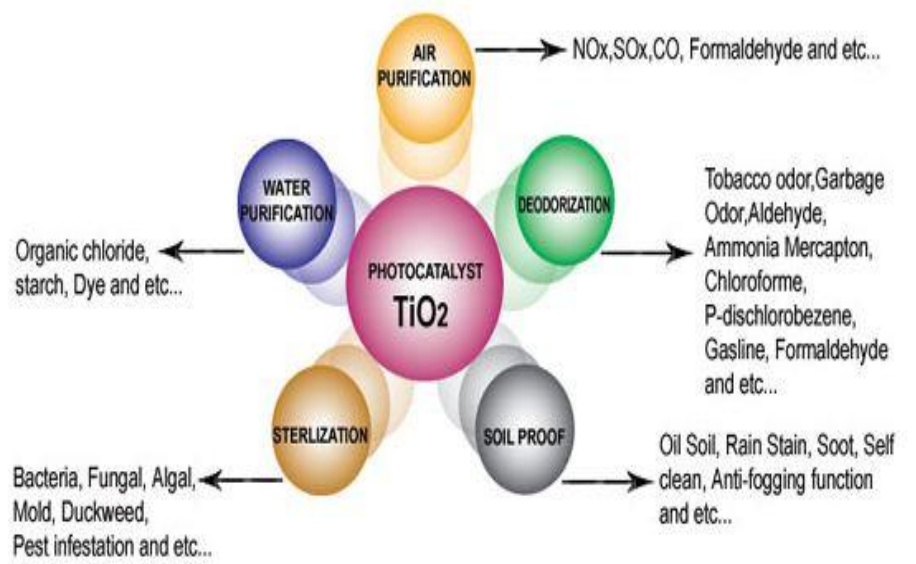

Fig 2 Green millennium applications [6]

\section{A-A the Product for interior coating: TPX-HL sol}

The TPX-HL sol green millennium product is strong oxidation to suppress microbial growth, odor, VOC removal which can be selected as a material for the interior coating of the case study building, shown in fig. 3 .

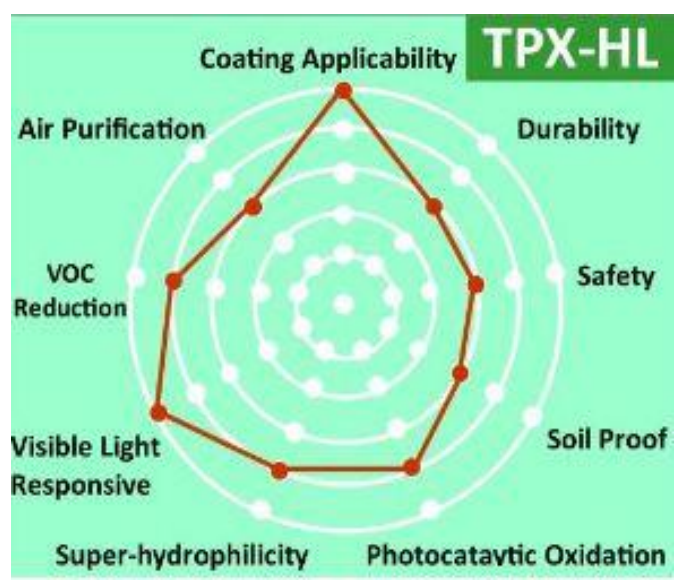

Fig 3 TPX-HL features [7]

\section{B. Enhanced Indoor Air Quality}

Photo-catalyst such as titanium dioxide had an effective way to get rid of organic poison and pollutant gases from the air. Photo-catalyst is classified under Nano materials category which is reflecting the global technological movement towards a better built environment. To improve energy efficiency and 
reduce a greenhouse gas the use of nanotechnology becomes the best solution. The following point of research discusses the impact of using Green millennium photo catalyst coating to promote occupants' comfort, well-being, and productivity by improving indoor air quality.

Green millennium coating improves the indoor air quality because it has a three-dimensional purifying technology which is different from the traditional air filtration with higher operating and overall maintenance costs. Hygienic photocatalyst treatment in green millennium continuously maintains a hygienic environment without any noise and maintenance concern. Simply turn on the light and let the purification process begin as shown in fig. 4 [8].

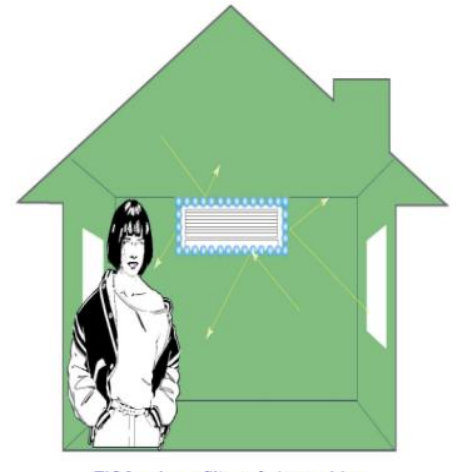

TiO2 only on filter of air machine

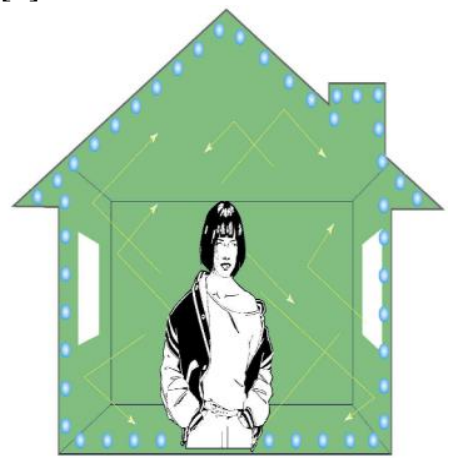

TiO2 functions everywhere.
Fig. 4 Traditional filtration vs. Green millennium coating [8]

\section{Enhanced Daylight and visual comfort}

High quality lighting helps to eliminate distractions, creates visual interest and a sense of place, supports interaction and communication, contributes to occupants' well-being, and reduces health problems [9]. Enhancing daylight is important for indoor spaces to connect building occupants to the outdoors and reduce the use of electrical lighting by introducing daylight into the space. The responsible for daylight permeability are building opening and glass so building window glass must be high transparency to allow daylight to pass through the material without being scattered.

Green millennium glass has a high transparency property, high infinite of water characteristic, reduces waters spotting; dirt and other residue cling to the glass readily. As water beads up, spots occur making the glass harder to clean and decrease its transparency, which affects its lighting permeability over the time. The green millennium hydrophilic glass is smoother than ordinary glass and more resistant to spotting as shown in fig. 5 .
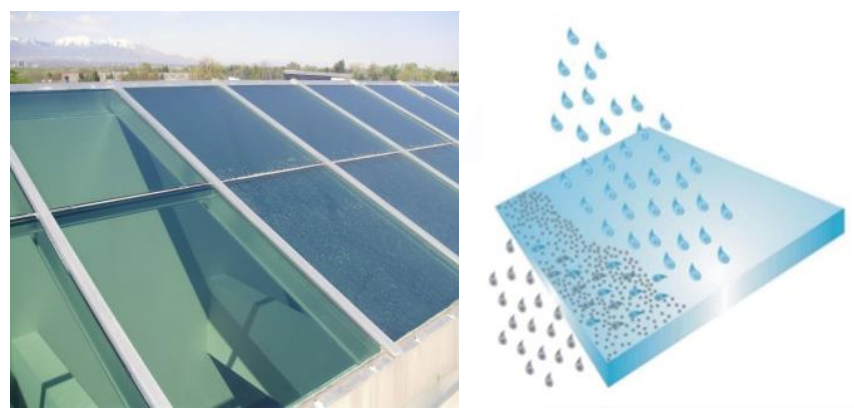

Fig .5 green millennium hydrophilic glass [10]

\section{$C-A$ the Product for glass: TPX-HPC sol}

The TPX-HPC is a combined technology of silica and titanium dioxide which is recommended for glass coating because it increases the super-hydrophilicity properties, reduce waters spotting and high transparency as shown in fig. 6 .

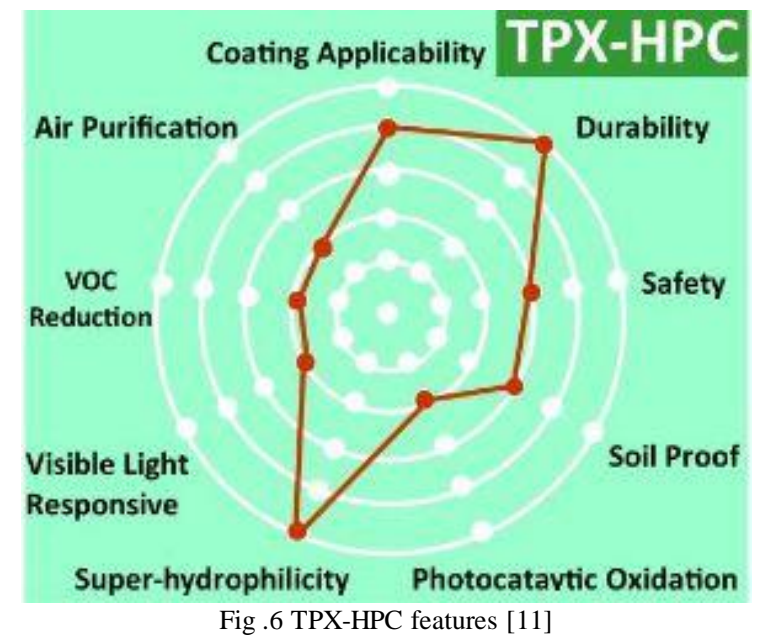

\section{Enhanced thermal comfort}

Thermal conditions inside buildings have a direct effect on people's satisfaction and performance. It is not associated only with air temperature, thermal comfort, but there are six primary factors must be considered concurrently (surface temperature, air temperature, humidity, air movement, metabolic rate and clothing). Modifying one or more of the six comfort factors can greatly improve occupants' perception of the thermal environment while still supporting energy reduction goals [2].

Nano TiO2 photo catalyst coating improved the thermal insulation property. Its advantages include a large refractive index, strong covering power, and good thermal performance. $\mathrm{TiO} 2$ has been gradually utilized as a pigment because of its greater solar reflectance [12]. 


\section{THE INDICATORS OF INDOOR ENVIRONMENTAL QUALITY CATEGORIES}

The indicators of IEQ categories evaluated by POE according to the building's users are classified as follow:

1- Indoor air quality

- Quality of air in rooms, studios, and labs (smelliness and dryness).

- Quality of air in toilets.

- Quality of air in the lobby, common spaces, and corridors.

- Overall indoor air quality.

2- Daylight and Visual comfort

- Adequacy and quality of natural lighting levels in all spaces.

- Adequacy and quality of artificial lighting levels in all spaces.

- Overall quality and adequacy of lighting in the building.

3- Thermal comfort

- Overall quality of thermal comfort (natural and artificial) of the building.

The second part of the post occupancy evaluation concerning the appearance of interior finishes and openings of the building's spaces according to the user's satisfaction and the researcher walkthrough observation as follow:

1- Quality and appearance of interior wall finishes

2- Quality, appearance, and presentation of the building's openings and windows.

\section{Post OCCUPANCY EVALUATION OF THE CASE STUDY BUILDING}

Architecture Department in Faculty of Engineering, Menoufia University was chosen as a case study of educational building. The category of educational buildings was chosen in particular because improving its efficiency will positively affect the student's health, social and academic level which will affect the whole society.

Post-Occupancy Evaluation is a process of systematically evaluating the performance of buildings after they are built and occupied for some time. This evaluation differs from other types of buildings' performance evaluations because it focuses on the needs and requirements of building users including health, safety, security, and functionality [13]. In this study a questionnaire survey will be developed and analyzed, then supplemented by a walk-through observation to evaluate the IEQ indicators and the interior appearance according to the satisfaction of the building users.

A. The analysis survey of building's IEQ indicators

A Simple random sampling of 80 students was taken which representing about $38 \%$ of total students in architecture department to know about the problems they face inside the building. The results revealed that the majority of students suffer from the IEQ problems shown in table 1 . The highest proportions of students suffer from the quality of thermal comfort which represents in natural and artificial ventilation. There is also a large percentage suffering from the quality and adequacy of daylighting in the building. Students explained through the interviews that these problems affect their educational level because they spend most of their time indoors in drawing and lecture halls. The following table evaluates the performance of IEQ indicators as Good, Medium and Poor which based on the user's satisfaction level.

TABLE I

RESULTS SURVEY FOR IEQ

\begin{tabular}{|c|c|c|c|c|}
\hline \multirow{2}{*}{\multicolumn{2}{|c|}{ POE of IEQ indicators }} & \multicolumn{3}{|c|}{$\begin{array}{c}\text { User's } \\
\text { satisfaction } \\
\text { level }\end{array}$} \\
\hline & & $\mathrm{P}$ & $\mathrm{M}$ & $\mathrm{G}$ \\
\hline \multirow{4}{*}{$\begin{array}{l}\text { Indoor } \\
\text { air } \\
\text { quality }\end{array}$} & $\begin{array}{l}\text { Quality of air in rooms, studios, } \\
\text { and labs }\end{array}$ & 40 & 30 & 10 \\
\hline & Quality of air in toilets & 30 & 25 & 25 \\
\hline & $\begin{array}{l}\text { Quality of air in the lobby, } \\
\text { common spaces, and corridors }\end{array}$ & 20 & 30 & 30 \\
\hline & Overall indoor air quality & 30 & 35 & 15 \\
\hline \multirow{3}{*}{$\begin{array}{l}\text { Daylight } \\
\text { and } \\
\text { Visual } \\
\text { comfort }\end{array}$} & $\begin{array}{l}\text { Adequacy and quality of natural } \\
\text { lighting levels in all spaces }\end{array}$ & 50 & 25 & 5 \\
\hline & $\begin{array}{l}\text { Adequacy and quality of } \\
\text { artificial lighting levels in all } \\
\text { spaces }\end{array}$ & 40 & 25 & 15 \\
\hline & $\begin{array}{l}\text { Overall quality and adequacy of } \\
\text { lighting in the building }\end{array}$ & 45 & 20 & 15 \\
\hline $\begin{array}{l}\text { Thermal } \\
\text { comfort }\end{array}$ & $\begin{array}{l}\text { Overall quality of thermal } \\
\text { comfort (natural and artificial) } \\
\text { of the building }\end{array}$ & 50 & 20 & 10 \\
\hline
\end{tabular}

The results obtained from the questionnaire indicated that the overall quality of indoor air is medium; the overall quality of daylight \& visual comfort and thermal comfort are poor. The percentage of each of them is shown in fig. 7.

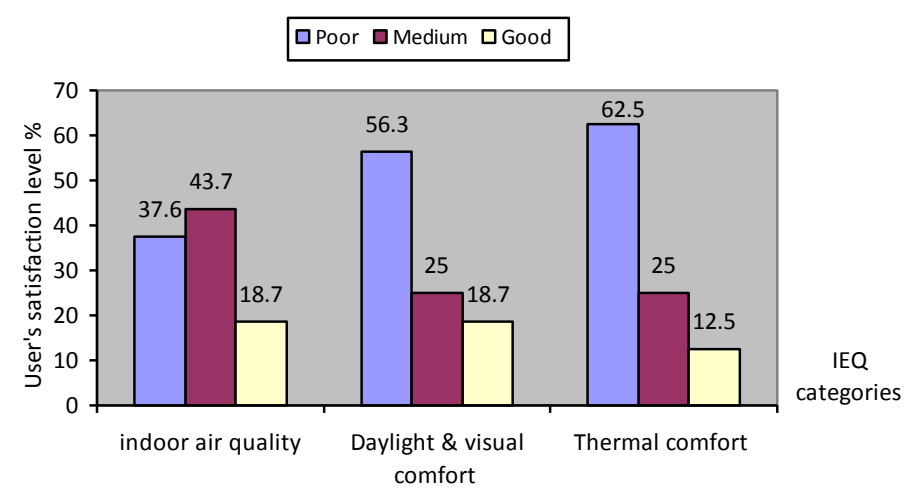

Fig. 7 The overall quality of building's IEQ (Researcher) 


\section{B. The analysis survey of interior appearance quality and walkthrough observation}

The following table evaluates the building interior appearance of walls and windows as good, medium and poor which based on the questionnaire of building's occupants.

TABLE II

RESULTS SURVEY FOR IAQ

\begin{tabular}{|l|c|c|c|}
\hline \multicolumn{1}{|c|}{ POE of IAQ indicators } & \multicolumn{3}{|c|}{ User's } \\
& \multicolumn{2}{|c|}{ satisfaction level } \\
\cline { 2 - 4 } & $\mathrm{P}$ & $\mathrm{M}$ & $\mathrm{G}$ \\
\hline $\begin{array}{l}\text { Overall quality and appearance of interior } \\
\text { walls finishes }\end{array}$ & 50 & 20 & 10 \\
\hline $\begin{array}{l}\text { Overall quality, appearance, and presentation } \\
\text { of the building's openings and windows. }\end{array}$ & 45 & 25 & 10 \\
\hline
\end{tabular}

The results obtained from the questionnaire indicated that the overall quality and appearance of the indoor walls and windows are poor as shown in fig 8 .

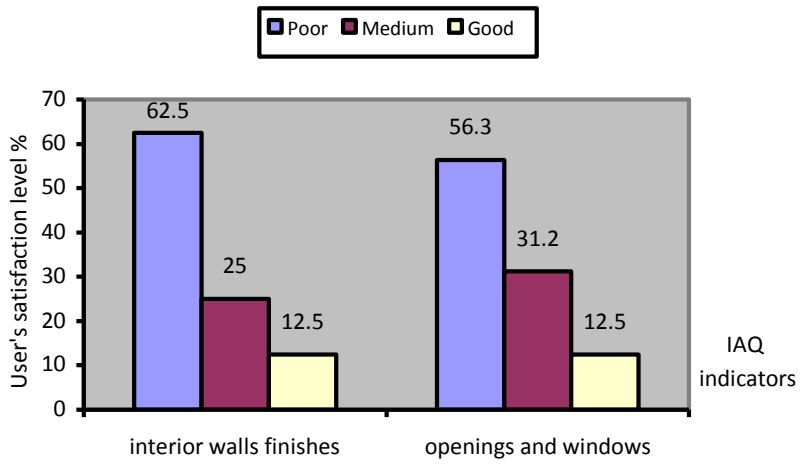

Fig. 8 The overall quality of building's IAQ (Researcher)

Walk through observations were conducted by taking a several photos to investigate the potential issues in the building indoor spaces. The following pictures expose the problems found indoors.
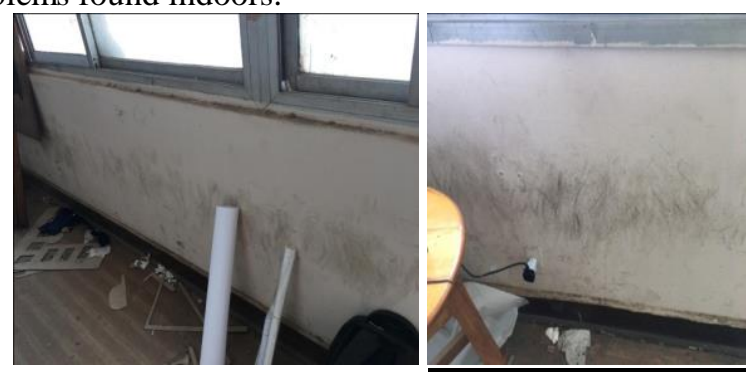

Picture 1: The current appearance of the building interior walls

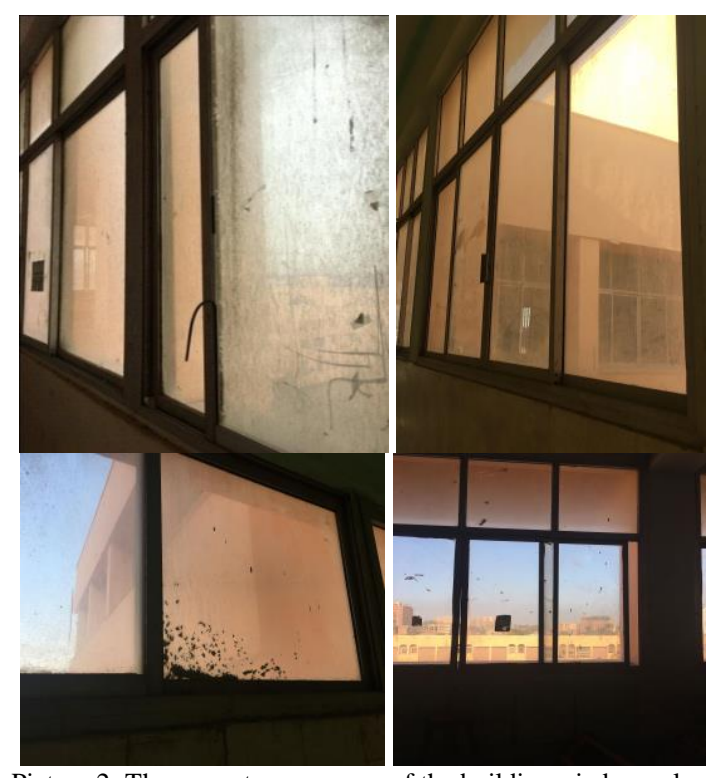

Picture 2: The current appearance of the building windows glass

\section{THE USAGE OF NANO PHOTO-CATALYST MATERIALS}

The results of the POE indicate the essential of using the Nano photo-catalyst materials for improving the IEQ of the selected building as follow:

1- Using green millennium products for indoor walls

- Using (TPX-HL) Nitrogen Doped Titanium Dioxide coating for interior walls which combines an air purification, VOC reduction, strong oxidation to suppress microbial and odour growth and responsive to indoor and outdoor light.

- The approximate cost of (TPX-HL) is $120 \$$ per litre, the area required for making the building coating renovation is $2900 \mathrm{~m} 2$ thus 290 litre will be required for this area (1 litre for $\mathrm{m} 2)$. The total cost is $34800 \$$.

2- Using green millennium products for glass windows

- Using (TPX-HPC) Silica / Titanium dioxide photocatalyst for glass which is high transparency, selfCleaning, safe and reduces waters spotting.

- The approximate cost of (TPX-HPC) is $125 \$$ per litre, the total area required for windows glass coating renovation is $680 \mathrm{~m} 2$ for 170 windows thus 68 litre will be required for this area (1 litre for $\mathrm{m} 2$ ). The total cost is $8500 \$$.

3 - Green Millennium Coating Procedure

- The most important factor after surface preparation and paint quality that contributes significantly to the life of a coating system is the proper application. 


\section{CONCLUSION}

The Nano materials are considered to be the foundation of a healthy indoor environment. Using the Nano photo-catalyst materials will improve the overall IEQ of the building; it positively affects the building's users. It constructs a longlasting building which means lower maintenance costs and reduces energy consumption, in addition to its effectiveness on improving indoor environmental quality and appearance. On the other hand, it maintains building user's health and increase the awareness of sustainable environment, in addition to its environmental, social and economic benefits.

\section{RECOMMENDATIONS}

1- It is recommended to insure the architects and designer's consciousness of using sustainable building materials in Egyptian buildings to regenerate the natural and social environments and will affects the national economy.

2- Improving indoor environmental quality should be a priority in the Egyptian construction law whether for new construction or retrofitting old buildings.

3- Promoting the use of Nano materials will greatly develop the construction sector in Egypt which is essential to keep up with the world's sustainable building developments and will impact on running costs, occupant well-being and business efficiency.

4- Citizens should be encouraged to promote a culture of sustainable environment which will positively affect the public society.

\section{REFERENCES}

[1] U.S. Green Building Council, Green Building 101: Sustainable materials and resources, June 2014

[2] Green Building Council, Inc. (USGBC). 2013. LEED V4 Reference Guide for Building Design and Construction. Washington, DC: USGBC pp 597, 657,697

[3] Egyptian Green Building Council, Arab Republic of Egypt Ministry of Housing, Utilities and Urban Development through the Housing and Building National Research, "The Green Pyramid Rating System", 2011. pp 23

[4] Green Millennium US Manufacture Representative, Designed by North Village Group Sitemap, Philadelphia, http://www.greenmillennium.com/features/

[5] Green Millennium US Manufacture Representative, Designed by North Village Group Sitemap, Philadelphia, LEED certification program. http://www.greenmillennium.com/leedcertification-program/

[6] Green Millennium US Manufacture Representative, Designed by North Village Group Sitemap http://www.greenmillennium.com/benefit/

[7] Green Millennium US Manufacture Representative, Designed by North Village Group Sitemap, PRODUCT INFO, TPX-HL Philadelphiahttp://www.greenmillennium.com/tpx-hl/

[8] Green Millennium US Manufacture Representative, Designed by North Village Group Sitemap, Philadelphia, Indoor/ interior application http://www.greenmillennium.com/indoor-interior/

[9] Federal Lighting Guide, eere.energy.gov/femp/pdfs/light_controls.pdf (accessed June 11, 2013).

[10] Green Millennium US Manufacture Representative, Designed by North Village Group Sitemap, http://www.greenmillennium.com/photo-inducedhydrophilicity/

[11] Green Millennium US Manufacture Representative, Designed by North Village Group Sitemap, PRODUCT INFO, TPX-HPC http://www.greenmillennium.com/tpx-hpc/

[12] Lu-wei Shen, Ya-mei Zhang, Pei-gen Zhang, Jin-jie Shi, and Zheng-ming Sun1, Effect of $\mathrm{TiO} 2$ pigment gradation on the properties of thermal insulation coatings,2016. pp 1

[13] C.F.F, Overview: A Summary of Finding, in Learning from Our Buildings: A State-of-the-Practice Summary of Post- Occupancy Evaluation, C.F.F, Editor 2001, National Academies Press: Washington, DC, USA. pp. 9 